\title{
Difficult tracheal intubation in randomized controlled studies: ethical considerations
}

\author{
Frederic Adnet, MD, PhD · Patricia Jabre, MD, PhD • \\ Frederic Lapostolle, MD, PhD
}

Received: 10 August 2009/Accepted: 3 September 2009/Published online: 20 October 2009

(C) Canadian Anesthesiologists' Society 2009

\section{To the Editor,}

We read with great interest the article by Thiboutot $e t$ al. published recently in the Journal. ${ }^{1}$ The authors evaluated the effects of manual in-line stabilization (MILS) of the cervical spine on the rate of difficult orotracheal intubation without cervical trauma in adult patients under general anesthesia. The study hypothesis was that the rate of failed tracheal intubation would be significantly greater with MILS than without. Although the results are convincing and the methodology seems correct, we believe this study raises an important ethical problem. While MILS is a maneuver frequently used while securing the airway of patients with a known or a potentially unstable cervical spine, its effect is known to impair visualization of the larynx with a reduction in the incidence of Cormack and Lehane's grade 1 laryngeal visualization and an increased incidence of grades 2,3 , and 4. ${ }^{2}$ In Thiboutot et al.'s study, $50 \%$ of patients in the MILS group had an unsuccessful intubation and a significantly longer time for successful tracheal intubation than the control group. Manual in-line stabilization was also associated with a negative impact on glottic exposure during laryngoscopy. In our opinion, the patients included in the MILS group had an exposure to an unacceptable iatrogenic morbidity because the predictable risk they might have incurred was not in proportion with the expected benefit. More frequent tracheal intubation attempts increase intubation difficulty, and it is known that difficult intubation is

F. Adnet, $\mathrm{MD}, \mathrm{PhD}(\varangle) \cdot \mathrm{P}$. Jabre, $\mathrm{MD}, \mathrm{PhD}$.

F. Lapostolle, MD, PhD

Hôpital Avicenne, Bobigny, France

e-mail: frederic.adnet@avc.aphp.fr

P. Jabre, $\mathrm{MD}, \mathrm{PhD}$

Inserm, U970, Paris, France associated with a higher rate of complications. ${ }^{3,4}$ Unfortunately, the incidence of side effects was not reported in this study. In our view, the prerequisites for ethical approval to conduct a randomized controlled trial should include confirmation that the intervention will not expose the test group to potential complications without complete disclosure to the patient of the associated risks and benefits.

Funding None.

Conflicts of interest None declared.

\section{References}

1. Thiboutot F, Nicole PC, Trepanier CA, Turgeon AF, Lessard MR. Effect of manual in-line stabilization of the cervical spine in adults on the rate of difficult orotracheal intubation by direct laryngoscopy: a randomized controlled trial. Can J Anesth 2009; 56: 412-8.

2. Nolan JP, Wilson ME. Orotracheal intubation in patients with potential cervical spine injuries. An indication for the gum elastic bougie. Anaesthesia 1993; 48: 630-3.

3. Benumof JL. Management of the difficult adult airway With special emphasis on awake tracheal intubation. Anesthesiology 1991; 75: 1087-110.

4. Peterson GN, Domino KB, Caplan RA, Posner KL, Lee LA, Cheney $F W$. Management of the difficult airway: a closed claims analysis. Anesthesiology 2005; 103: 33-9.

\section{Reply}

We thank Drs. Adnet et al. for their interest in our article. However, we are somewhat surprised by the ethical concerns that have been raised. Over the past several decades, Canada has been a leader in developing an ethical framework for clinical research involving humans, namely, the Tri-Council Policy Statement. ${ }^{1}$ Our study complied 
entirely with those guidelines. As clearly stated in the methods section of our manuscript, the study protocol and the consent form were approved by the Research Ethics Board (REB) of our institution. ${ }^{2}$ During the enrollment phase, the study was explained to each eligible subject and all patient questions were answered as part of the informed consent process. During the editorial review process, there was no expression of concern regarding any ethical issues related to our study.

Although we agree that it was known that manual in-line stabilization (MILS) impairs visualization of the larynx and worsens the Lehane's grade of laryngoscopy, the actual impact of MILS on the success rate of endotracheal intubation had not been adequately assessed. Therefore, we believe that there was a sound rationale for having conducted this study. For safety reasons, the research protocol excluded any patient with a history of difficult tracheal intubation or difficult mask ventilation, and it explicitly called for termination of the laryngoscopy and release of the MILS maneuver should the patient's oxygen saturation decrease to $<90 \%$ at any time. No complication or serious adverse event was observed in any patient, and no patient in the MILS group suffered any morbidity. As we reported in our article, for any patient in the MILS group whose trachea could not be intubated on the first attempt, tracheal intubation was uniformly successful on the second attempt after MILS was withdrawn. However, near the mid-point of data collection, the investigators began to suspect that that there was a clinically important between-groups difference in the tracheal intubation failure rate. We therefore decided to suspend patient enrollment while an interim analysis was undertaken. As we reported, the results of the interim analysis led to termination of the study after enrolling 200 of the projected 510 subjects originally deemed necessary to achieve sufficient statistical power.

We recognize and appreciate that no randomized controlled trial is without risk. The role of REBs is not only to review and to grant approval of study protocols but also to review any protocol amendments and to receive reports and close-out documentation from the investigators. There is also an important role served by data monitoring and patient safety committees. As a condition of publication, peerreviewed journals require researchers to obtain appropriate ethical approval and to adhere to the accepted standards when they conduct research in humans or conduct studies on animals. However, it is unquestionable that minimizing the risks for the patients and weighing these risks, both known and unknown, against the potential gain of scientific knowledge is a key responsibility of all investigators participating in a clinical trial. We believe that we have fulfilled this duty.

Funding None.

Conflicts of interest None declared. Dr. Turgeon is a clinical research scholar of the Fonds de la Recherche en Santé du Québec (FRSQ).

\section{References}

1. Canadian Institutes of Health Research; Natural Sciences and Engineering Research Council of Canada; Social Sciences and Humanities Research Council of Canada. Tri-Council Policy Statement: Ethical Conduct for Research Involving Humans, 1998 (with 2000, 2002 and 2005 amendments). Available from URL: http://www.pre.ethics.gc.ca/policy-politique/tcps-eptc/docs/TCPS\% 20October\%202005_E.pdf. Accessed August 2009.

2. Thiboutot F, Nicole PC, Trepanier CA, Turgeon AF, Lessard MR. Effect of manual in-line stabilization of the cervical spine in adults on the rate of difficult orotracheal intubation by direct laryngoscopy: a randomized controlled trial. Can J Anesth 2009; 56: 412-8.

Martin R. Lessard, MD

François Thiboutot, MD

Alexis F. Turgeon, MD

Pierre C. Nicole, MD

Claude A. Trépanier, MD

Department of Anesthesiology and Centre de Recherche du CHA

(Hôpital de l'Enfant-Jésus), Unité de Traumatologie - Urgence Soins Intensifs, Université Laval, Québec, Québec, Canada 